\title{
Foreword
}

\section{Fatigue and Corrosion Damage in Metallic Materials}

This special forum in Metallurgical and Materials Transactions A contains the peer-reviewed papers that were presented at the Symposium on Fatigue and Corrosion Damage in Metallic Materials: Fundamentals, Modeling and Prevention, at the 2011 TMS Annual Meeting \& Exhibition, held between February 27, 2011 and March 3, 2011 in San Diego, CA. This symposium featured new discoveries and advances in the investigation and simulation of fatigue and corrosion damage, identification of fatigue weak-links, enhancement of fatigue strength and corrosion resistance, quantitative relationship between microstructures and fatigue/corrosion properties, life prediction, among others.

The organizers, Professor Tongguang Zhai of the University of Kentucky, Dr. Zhengdong Long of Kaiser Aluminum, and Professor Peter K. Liaw of the University of Tennessee, of this symposium wish to thank the TMS Mechanical Behavior Committee for sponsoring the symposium and the contributions of the authors. They wish to express their gratitude to Professor David E. Laughlin, Principal Editor, and Ms. Dora Moscatello, Production Editor, for processing and accepting the papers as a Special Symposium in Metallurgical and Materials Transactions A.

Guest Editors

Tongguang Zhai Associate Professor, University of Kentucky, 177 F. Paul Anderson Tower, Lexington, KY 40506

Peter Liaw

Professor and Ivan Racheff Chair of Excellence, The University of Tennessee, 427-B Dougherty Engineering Bldg., Knoxville, TN 37996-2200 